\title{
Implementation of an innovative surgical pharmacy service to improve patient outcomes-Twelvemonth outcomes of the Enhanced Surgical Medicines Optimization Service
} DOI:

10.1111/jcpt.13014

\section{Document Version \\ Accepted author manuscript}

Link to publication record in Manchester Research Explorer

Citation for published version (APA):

Bansal, N., Tai, W-T., \& Chen, L-C. (2019). Implementation of an innovative surgical pharmacy service to improve patient outcomes-Twelvemonth outcomes of the Enhanced Surgical Medicines Optimization Service. Journal of clinical pharmacy and therapeutics. https://doi.org/10.1111/jcpt.13014

Published in:

Journal of clinical pharmacy and therapeutics

\section{Citing this paper}

Please note that where the full-text provided on Manchester Research Explorer is the Author Accepted Manuscript or Proof version this may differ from the final Published version. If citing, it is advised that you check and use the publisher's definitive version.

\section{General rights}

Copyright and moral rights for the publications made accessible in the Research Explorer are retained by the authors and/or other copyright owners and it is a condition of accessing publications that users recognise and abide by the legal requirements associated with these rights.

\section{Takedown policy}

If you believe that this document breaches copyright please refer to the University of Manchester's Takedown Procedures [http://man.ac.uk/04Y6Bo] or contact uml.scholarlycommunications@manchester.ac.uk providing relevant details, so we can investigate your claim.

\section{OPEN ACCESS}


Implementation of an innovative surgical pharmacy service to improve patient outcomes - twelve-month outcomes of the Enhanced Surgical Medicines Optimisation Service

Authorship: Neetu Bansal ${ }^{1}$, Wan-Tien Tai ${ }^{2}$, Li-Chia Chen²

${ }^{1}$ Ms. Neetu Bansal, Lead Enhanced Recovery Surgical pharmacist. Department of Pharmacy, Manchester University Hospitals NHS Trust, Oxford Road, Manchester, M13 9WL, UK.

Email - neetu.bansal@mft.nhs.uk

${ }^{2}$ Ms. Wan-Tien Tai, Research intern. Centre for Pharmacoepidemiology and Drug Safety, Division of Pharmacy and Optometry, School of Health Sciences, Faculty of Biology, Medicine and Health, University of Manchester, Manchester Academic Health Science Centre. Oxford Road, Manchester, M13 9PT, UK

Email -wantien@gmail.com

${ }^{2}$ Dr. Li-Chia Chen, Senior Lecturer, Centre for Pharmacoepidemiology and Drug Safety, Division of Pharmacy and Optometry, School of Health Sciences, Faculty of Biology, Medicine and Health, University of Manchester, Manchester Academic Health Science Centre. Oxford Road, Manchester, M13 9PT, UK

Email - li-chia.chen@manchester.ac.uk

\section{Correspondence:}

Ms. Neetu Bansal

Address: Department of Pharmacy, Manchester University Hospitals NHS Trust, Oxford Road, Manchester, M13 9WL, UK.

Telephone: +44 (0) 1617014327 
Email: neetu.bansal@mft.nhs.uk

Word count (excluding title page, abstract, references, figures and tables): 2758 words 


\section{Abstract}

\section{What is known and objective}

3 Pharmacists play vital roles in medicines optimisation in different care settings. Studies have

4 shown that optimising patient's pre-existing co-morbidities prior to surgery leads to better

5 post-operative outcomes. The Enhanced Surgical medicines optimisation service (ESMOS)

6 is an innovative surgical pharmacy service introduced at a large teaching hospital in the UK

7 in September 2017 which aimed to reduce the length of stay and postoperative

8 complications in general surgical patients. This purpose of this study is to evaluate the

9 implementation and outcomes of this service at 12 months after it was rolled out.

\section{Methods}

This cohort study was undertaken between September 2017 and September 2018. Adult patients undergoing elective major general surgical procedures were included and stratified into four sub-specialties, including hepato-pancreato-biliary (HPB), upper gastrointestinal (GI), lower $\mathrm{Gl}$ and vascular surgery. Patient undergoing emergency and day case procedures or with missing outcome data were excluded from this study. Patients' demographics, baseline co-morbidities, high-risk medications, American Society of Anaesthesiologists (ASA) physical status classification, surgical procedure, post-operative complications, length of stay and nature of pharmacist interventions were collected and reported by descriptive statistics.

\section{Results and discussion}

A total of 246 patients were included in the four general sub-specialties: HPB $(n=82)$, upper GI (n=17), lower $G \mid(n=87)$ and vascular $(n=60)$. There was a significant reduction in the median length of stay in three surgical specialties: lower GI (median reduction: -2; IQR: -4, 1.8; $\mathrm{P}=0.038$ ), HPB (median reduction: $-4.5 ; \mathrm{IQR}:-7,-1 ; \mathrm{P}=0.001$ ) and vascular (median reduction: -2; IQR: $-4,0 ; \mathrm{P}=0.043)$. 


\section{What is new and conclusion}

30 The ESMOS model is a novel care pathway that allows both early identification of medicines

31 optimisation and peri-operative drug management issues in surgical patients hence

32 promoting quicker recovery after surgery and reducing the overall length of stay.

33

34 Keywords: Pharmacist-led; length of stay; postoperative complications; elective surgery; 35 medicines optimisation. 
37 Post-operative complications after major surgery are well documented in the literature with complication rates as high as $30 \%$ having been reported. ${ }^{1-6}$ Complications may vary in severity from wound infections to more severe events, such as anastomotic leaks, wound dehiscence or even post-operative mortality. ${ }^{7}$ Factors associated with increased risk of postoperative complications include advanced age, co-morbidities such as diabetes and those related to cardiovascular disease along with undergoing major emergency surgery. ${ }^{3-4,8,9}$ In line with the emphasis on both quality and cost-effectiveness in the NHS, there is a need to re-organise the healthcare workforce to provide a multi-disciplinary model of care with the focus on optimising these pre-existing co-morbidities prior to surgery. ${ }^{10}$

To improve patient outcomes and reduce length of stay for surgical patients, the National Enhanced Recovery Programme was introduced in 2009 by collaboration by the Department of Health in partnership with NHS improvement, the National Cancer Action Team and the NHS Institute for Innovation and Improvement. ${ }^{11}$ In line with this initiative, a pharmacist led Enhanced Surgical Medicines Optimisation Service (ESMOS) was implemented in a large 1200-bedded tertiary hospital in Central Manchester in September 2017 to mitigate the risks of post-operative complications and optimise post-operative care. The goals of the ESMOS service are to identify high-risk surgical patients once they are listed for surgery and get them in the best possible state for operation by focusing on optimising their pre-existing comorbidities.

57

During the pre-operative phase, patients are reviewed in a virtual pharmacist clinic whereby patients' pre-existing medical co-morbidities are recorded by pharmacists along with any high-risk medication the patient is taking. ${ }^{12}$ In the post-operative phase, all patients are closely monitored on the ward with the focus being on medicines optimisation to minimise

62 the incidence of any post-operative complications occurring. This involves working collaboratively with the wider multi-disciplinary team including anaesthetists, surgeons, 
specialist nurses, dieticians, physiotherapists along with both pharmacists and general practitioners in the community.

Prior to the implementation of ESMOS, a pilot study was undertaken between 2013 and 2016 on 100 patients admitted for major colorectal surgery before $(n=50)$ and after $(n=50)$ the introduction of ESMOS. This involved dedicated pharmacist involvement throughout the patient journey from the pre-operative stage to discharge post-surgery with a focus on medicines optimisation. Baseline data were collected on all patients seen pre-operatively in a nurse led pre-admission clinic. The results showed a significant reduction in both length of stay and the incidence of postoperative complications. ${ }^{13}$ Based on these positive results, the trust recruited additional senior surgical pharmacists and a pharmacy technician to provide the ESMOS service.

The ESMOS was initially rolled out to four main general surgical sub-specialities: hepatopancreato-biliary (HPB), upper gastrointestinal (GI), lower $\mathrm{Gl}$ and vascular surgery. Each speciality was allocated one specialist surgical pharmacist with independent prescribing status along with a pharmacy technician to support the service. A list of 'always events'14 (Appendix 1) was used to guide the ESMOS delivery to ensure optimal patient experience, improve outcomes and serve as a unifying force for all that demonstrates an on-going commitment to person and family centred care.

Patients who were eligible to receive the service were identified by the pharmacist technician through various methods (liaising with consultant secretaries and gaining access to scheduled calendars and access to the surgeon's lists) and by direct referrals to the service. Eligible patients were subsequently grouped into either 'low risk 'or 'high risk' by a risk screening tool (Appendix 2) which was developed by expert pharmacist consensus considering patients' co-morbidities, type of surgery and medications. For 'high-risk' patients, a telephone consultation was arranged by the pharmacist to identify any medicines 
92 optimisation issues. In addition, an anaemia assessment was undertaken for both low and 93 high-risk patients and those who are subsequently identified as being anaemic from their 94 biochemistry results were referred to haematology for iron replacement therapy.

95

96 To inform the further service expansion and improvement strategies, an iterative service 97 evaluation is needed to guide the continuous service improvement process. This project 98 aimed to assess the implementation of the ESMOS service and evaluate its impacts on 99 postoperative care outcomes. 
101 Study design and data source

102 A retrospective cohort study was conducted using a registry collected by the ESMOS 103 pharmacists prospectively during the individual patient admission from September 2017 104 (launch of service) to September 2018. The registry is an electronic database containing relevant information of all patients included in the service, including patient demographics (e.g. age, gender), the American Society of Anaesthesiologists (ASA) score for physiological status, ${ }^{15}$ co-morbidities, details of high-risk medication, nature of pharmacist interventions, post-operative complications, length of stay and details of any re-admissions. Data confidentiality was maintained with access restricted by password protection only to the ESMOS team. Anonymous data was extracted for data analysis purposes. Ethics approval was not required for this service evaluation.

\section{Study cohort}

114 All adult patients who underwent major elective general surgical procedures with an ASA grade of more than or equal to 2 (i.e. a patient with a mild systemic disease) ${ }^{15}$ during the study period were included. Patients who underwent planned day case or emergency surgery, and those with missing data of primary outcome were excluded. Included patients were further categorised into the four main general surgical sub-specialties that the ESMOS service covered in the hospital: HPB, upper GI, lower GI and vascular surgery.

\section{Outcome measure}

122 Information recorded included: baseline patient characteristics, including demographics 123 (gender, age), ASA grade (scored between 1 to 5), co-morbidities and any high-risk medicines taken before the surgery. Types of pharmacist interventions as well as all complications reviewed by the relevant surgical teams were also extracted. The interventions made by pharmacists were themed into two different categories, i.e. those related to peri-operative drug management or those pertaining to medicines optimisation. 
Peri-operative drug management covered all issues that arose because of the surgery, such as peri-operative drug management advice, post-operative nausea and vomiting, optimising analgesic control, electrolyte correction and infection monitoring. Medicines optimisation interventions included actions that led to better management of patients pre-existing medical conditions. These included better blood pressure control, optimising diabetes management, compliance with inhalers and optimisation of heart failure medication.

The primary outcome was the actual length of stay (ALOS), which was calculated as the continuous time-period (days) of each inpatient spell. The nationally expected length of stay (ELOS) for corresponding major elective surgical procedures ${ }^{12}$ was also retrieved and compared with each patient's ALOS.

\section{Data analysis}

141 Descriptive data was used to report the results, including mean and standard deviation (SD)

142 or median and interquartile range (IQR) for the length of stay, and proportion for the 143 categorical variables, such as gender, age rank and ASA grade. For each patient, the 144 reduction in length of stay was calculated using the Wilcoxon signed rank test. All data analysis was conducted by using an online software package - Stats Pages (statpages.org).

\section{Results}

\section{Study cohort}

149 During the 12-month period, 544 patients were identified as potentially eligible for the 150 ESMOS service, with 271 patients classified as 'high risk' and enrolled into the service.

151 Twenty-one patients were excluded due to cancellation of surgery or whereby the surgeon considered that surgery was not appropriate due to disease progression. Of the 250 patients

153 who received the ESMOS service, 4 patients were excluded due to missing data. In total, 154246 patients were included in this study and classified into HPB ( $n=82)$, upper $\mathrm{GI}(\mathrm{n}=17)$, 155 lower $\mathrm{GI}(\mathrm{n}=87)$ and vascular (n=60) group (Figure 1). 
157 Characteristics of patients and pharmacist interventions

158 Of the 246 patients included in this study (Table 1), there were significantly more males than 159 females $(69.1 \%$ vs. $30.9 \%$; $\mathrm{P}<0.05)$. The majority of patients fell in the $60-69(35.7 \%)$ and $160 \quad 70-79$ (36.9\%) year age groups and most patients ASA grade being greater than or equal to 161 2 (58.9\%). Cardiovascular disease was the most prevalent co-morbidity (36.3\%).

162

163 Anti-platelets $(n=122)$, anticoagulants $(n=49)$ and angiotensin-converting enzyme inhibitors $164(n=113)$ were the most frequently identified high-risk drugs. In total, there were 420 interventions undertaken by pharmacists, including $186(44.3 \%)$ interventions related to medicines optimisation and $234(55.7 \%)$ interventions related to peri-operative drug management (Table 2).

\section{Length of stay}

170 The median length of stay for the four surgical sub-specialities were: 20 (IQR: 11.5, 32.3), 8 171 (IQR: 6, 11), 11.5 (IQR: 8.5, 15.8), and 6 (IQR: 4, 9.3) days for upper GI, lower GI, HPB and vascular surgery groups respectively, comparing again the corresponding expected length of stay (ELOS): 14 (IQR: 14, 14), 10, (IQR:10, 10), 14 (IQR: 11, 14), and 10 (IQR: 7, 10) days

\section{4 (Figure 2).}

175

Furthermore, there was a significant reduction in the median length of stay in the lower GI

177 (median reduction: -2; IQR: -4, 1.8; P=0.038), HPB (median reduction: -4.5; IQR: -7, -1; $\mathrm{P}=0.001$ ) and vascular (median reduction: $-2 ; \mathrm{IQR}:-4,0 ; \mathrm{P}=0.043$ ) surgical sub-specialities. The median ALOS was longer than median ELOS in the upper GI speciality (median reduction: 5; IQR: $-3,17 ; \mathrm{P}=0.055)$, although it was not significant. Overall, the total length of stay reduction in patients whose ALOS fell in the $25^{\text {th }}$ to $75^{\text {th }}$ percentile range was -96 days in lower GI, -81 days in HPB and -104 days in vascular sub-specialities, which summed up to -281 days. 


\section{Post-operative complications}

Overall, $118(48.0 \%)$ patients experienced postoperative complications, and the proportion of patients who experienced postoperative complications was higher in the upper GI surgery group $(n=13 ; 76.5 \%)$, followed by the lower $\mathrm{GI}(n=44 ; 50.6 \%)$, vascular $(n=27 ; 45.0 \%)$ and HPB surgery $(n=34 ; 41.5 \%)$. Of all the 275 episodes of complications (Table 3), postoperative nausea and vomiting $(n=61 ; 22.2 \%)$ was the most frequently identified surgery related complication, followed by infections $(n=50 ; 18.2 \%)$ and cardiac issues $(n=25 ; 9.1 \%)$.

\section{Discussion}

To our knowledge, this research is the first to assess the short-term outcomes of an innovative surgical pharmacy-led service model to enhance surgical care. The results demonstrated a significant reduction in length of stay for service receivers in the lower $\mathrm{GI}$, HPB and vascular surgical sub-specialities in comparison with the corresponding expected length of stay by the national standard. The results of this study support the feasibility to further evaluate the impact of ESMOS in a prospective study.

Pharmacists' impact on the outcome of chronic disease management and medicine optimisation have been well documented in the literature, in particular in managing the use of high-risk medicines. As documented in the literature, anti-platelets, anticoagulants and angiotensin-converting enzyme inhibitors were the most frequently identified high-risk drugs, and cardiovascular disease was the most prevalent co-morbidity in patients scheduled for surgery. ${ }^{16}$ In a meta-analysis reported by Machado et al (2007) which included 2246 patients from 13 controlled (randomised, single arm and non-randomised) trials, and found that systolic blood pressure was significantly reduced following pharmacist's intervention, while it remained unchanged in the standard care group. ${ }^{17}$ 
211 The ESMOS users had a significant reduction in length of stay compared with the expected

212 length of stay in those within lower GI, HPB and vascular sub-specialities but not within the

213 upper GI sub-speciality. This could be due to the small patient numbers in this group.

214 Additionally, patients who underwent upper GI surgery tended to have longer hospital stays

215 due to ongoing anastomotic leaks and infections hence need for extended courses of

216 intravenous antibiotics.

217

218 A reduction in length of stay (median reduction: - 2 days) was observed within those who 219 received vascular surgery. The trust is a recognised tertiary referral centre for vascular cases, and the service is strongly supported by a vascular specialist nurse who also referred patients to the ESMOS pharmacist pre-operatively. This streamlining of prioritisation of resources may also contribute to this reduction in length of stay effect observed.

223

Similarly, the trust is also a tertiary referral centre for HPB surgery within the region, hence it tends to receive patients with very complex cases. There was a substantial reduction in length of stay (median reduction: -4.5 days) within those patients who underwent HPB surgery. This could also be due to other interventions such as the implementation of a regional jaundice pathway to improve patients' outcomes, recruitment of a jaundice clinical nurse specialist and the introduction of a prehabilitation programme led by both a specialist dietitian and a physiotherapist with the aim of getting patients in the best possible state for surgery.

For patients who received lower GI surgery, a decrease in length of stay (median reduction: -2 days) was also observed. This reduction was observed despite there being some disruptions in the provision of lower Gl services within the trust with two stoma nurses leaving posts within the study period. Consequently, patients with a stoma might wait longer

237 for a review by a stoma nurse or may have inadequate stoma output prolonging their hospital stay. 
240 In addition, post-operative complications are a significant source of morbidity and mortality 241 and have been shown to increase the length of stay. ${ }^{18}$ In our study, $48 \%$ of patients who 242 underwent a surgical procedure developed at least one postoperative complication. The most frequently observed complications were postoperative nausea and vomiting, followed by infections and cardiac issues.

This study demonstrates the importance of a multi-disciplinary team approach to patient care and in particular the invaluable role of the pharmacy team which is often overlooked and undervalued. Although it analysed a short-term outcome, the potential cost savings which can be achieved through the reduced length of stay far outweigh the costs of setting up the service. As a result of dedicated pharmacist input pre-operatively, patient's co-morbidities are optimised before surgery taking the pressure off primary care and ensuring that interventions are acted upon promptly. This may have an impact on patient's quality of life and GP workload both pre- and post-operatively.

However, as the ESMOS is a new service model, the results of this study were limited by a lack of comparison. The ESMOS model warrants further validation using a rigorous comparative analysis to routine care, ideally in the form of a prospective randomised clinical trial. Nevertheless, the evaluation of service delivery and improvement is an iterative process and using real-world data, such as comparing services in different hospital settings or using the historical comparator group could be an alternative. ${ }^{19}$

At the time of manuscript submission, another hospital part of the same trust has also funded the replication of ESMOS model within the urology sub-speciality. Evaluation of ESMOS implementation at other sites will help further validate findings from this study. In addition, to ensure the efficient implementation of the service, a process evaluation to identify the key factors influencing the process of implementation are also important. ${ }^{20}$ 
268 A patient and public involvement (PPI) group was also set up as part of the ESMOS service 269 which included around 12 patients who had received the service. Patient users from the 270 group felt the ESMOS service was invaluable to their surgical journey. Patients who received 271 the service felt the continuity of care and contact with a healthcare professional were critical 272 elements of the service.

273

\section{Conclusion}

275 The results of this study reaffirm the importance of a holistic and multi-disciplinary approach 276 to patient care, with a positive effect of dedicated pharmacist input through the patient 277 journey, starting pre-operatively until discharge post-surgery. Further study is needed to 278 validate our findings ideally in the form of a prospective randomised controlled trial.

279

\section{Contributors}

281 NB: concept of study, execution of study and write up. SW: Data management and 282 interpretation of results. LCC: interpretation of results and write up.

\section{Competing interests and funding}

285 None declared.

\section{Ethics approval}

288 Ethics approval was not required as this was an existing service evaluation.

\section{Acknowledgements and affiliations}

291 We would like to thank the surgical pharmacy team at the Manchester University Hospitals 292 NHS Trust for their help with the data collection for this study. 


\section{References}

1. Jakobson T, Karjan J, VIP L et al. Postoperative complications and mortality after major gastrointestinal surgery. Medicine 2014; 50 (2): 111-117.

2. Jhanji S, Thomas B, Ely A et al. Mortality and utilisation of critical care resources amongst high-risk surgical patients in a large NHS Trust. Anaesthesia 2008; 63: 695-700.

3. Pearse RM, Harrison DA, James $P$ et al. Identification and characterisation of the high risk surgical population in the United Kingdom. Crit Care 2006; 10 (3): R81.

4. Longo WE, Virgo KS, Johnson FE et al. Risk factors for morbidity and mortality after colectomy for colon cancer. Dis Colon Rectum 2000; 43(1):83-91.

5. Mayo NE, Feldman L, Scott S et al. Impact of preoperative change in physical function on postoperative recovery: argument supporting prehabilitation for colorectal surgery. Surgery 2011; 150(3):505-14.

6. Pinto A, Faiz O, Davis $\mathrm{R}$ et al. Surgical complications and their impact on patients' psychosocial well-being: a systematic review and meta-analysis. BMJ Open 2016; 6: e007224.

7. Fink C, Diener MK, Bruckner T et al. Impact of preoperative patient education on prevention of postoperative complications after major visceral surgery: study protocol for a randomized controlled trial (PEDUCAT trial). Trials 2013; 14:271.

8. Cullinane M, Gray AJ, Hargraves CM et al. The 2003 Report of the National Confidential Enquiry into Peri-Operative Deaths. London: NCEPOD, 2003.

9. Heriot AG, Tekkis PP, Smith JJ et al. Prediction of postoperative mortality in elderly patients with colorectal cancer. Dis Colon Rectum 2006; 49: 816-824. 
10. Partridge J, Sbai M, Dhesi J. Proactive care of older people undergoing surgery. Aging Clin Exp Res 2018 ;30(3):253-257.

11.Simpson JC, Moonesinghe SR, Grocott MP et al. Enhanced recovery from surgery in the UK: an audit of the enhanced recovery partnership programme 2009-2012. British Journal of Anaesthesia 2015; 115 (4): 560-8.

12. Miah S, Dunford C, Edison M et al. A prospective clinical, cost and environmental analysis of a clinician-led virtual urology clinic. Annals of the Royal College of Surgeons of England 2018, 101(1); 30-34

13. Bansal, N. Impact of pharmacist involvement in enhanced recovery pathways in improving patient care in those undergoing lower gastrointestinal surgery. National Institute for Health and Care Excellence Shared learning database; 2016. Last accessed $10^{\text {th }}$ January 2019. Available at: https://www.nice.org.uk/sharedlearning/impact-of-pharmacist-involvement-inenhanced-recovery-pathways-in-improving-patient-care-in-those-undergoinglower-gastrointestinal-surgery.

14. Institute for Healthcare Improvement for NHS England. Always events toolkit. December 2016. Last accessed $4^{\text {th }}$ January 2019. Available at https://www.england.nhs.uk/wp-content/uploads/2016/12/always-events-toolkitv6.pdf.

15. ASA House of Delegates. ASA Physical Status Classification system 2014. Last $\begin{array}{llll}\text { accessed } & 10^{\text {th }} \quad \text { January } & 2019 . & \text { Available }\end{array}$ http://www.asahq.org/resources/clinical-information/asa-physical-statusclassification-system. 
16. Howard R, Avery A, Slavenburg $S$ et al. Which drugs cause preventable admissions to hospital? A systematic review. $\mathrm{Br}$ J Clin Pharmacol 2007; 63 (2):136-47.

17. Machado M, Bajcar J, Guzzo GC et al. Sensitivity of patient outcomes to pharmacist interventions. Part II: Systematic review and meta-analysis in hypertension management. Ann Pharmacother 2007; 41 (11):1770-81.

18. McAleese P, Odling-Smee W. The effect of complications on length of stay. Annals of Surgery 1994; 220 (6): 740-44.

19. Craig P, Dieppe $\mathrm{P}$, Maclntyre $\mathrm{S}$ et al. Developing and evaluating complex interventions: the new Medical Research Council guidance. BMJ 2008; 337:a1655.

20. Moore GF, Audrey S, Barker $M$ et al. Process evaluation of complex interventions: Medical Research Council guidance. BMJ 2015; 350:h1258. 


\section{References}

1. Jakobson T, Karjan J, VIP L et al. Postoperative complications and mortality after major gastrointestinal surgery. Medicine 2014; 50 (2): 111-117.

2. Jhanji S, Thomas B, Ely A et al. Mortality and utilisation of critical care resources amongst high-risk surgical patients in a large NHS Trust. Anaesthesia 2008; 63: 695-700.

3. Pearse RM, Harrison DA, James $P$ et al. Identification and characterisation of the high risk surgical population in the United Kingdom. Crit Care 2006; 10 (3): R81.

4. Longo WE, Virgo KS, Johnson FE et al. Risk factors for morbidity and mortality after colectomy for colon cancer. Dis Colon Rectum 2000; 43(1):83-91.

5. Mayo NE, Feldman L, Scott S et al. Impact of preoperative change in physical function on postoperative recovery: argument supporting prehabilitation for colorectal surgery. Surgery 2011; 150(3):505-14.

6. Pinto A, Faiz O, Davis R et al. Surgical complications and their impact on patients' psychosocial well-being: a systematic review and meta-analysis. BMJ Open 2016; 6: e007224.

7. Fink C, Diener MK, Bruckner T et al. Impact of preoperative patient education on prevention of postoperative complications after major visceral surgery: study protocol for a randomized controlled trial (PEDUCAT trial). Trials 2013; 14:271.

8. Cullinane M, Gray AJ, Hargraves CM et al. The 2003 Report of the National Confidential Enquiry into Peri-Operative Deaths. London: NCEPOD, 2003.

9. Heriot AG, Tekkis PP, Smith JJ et al. Prediction of postoperative mortality in elderly patients with colorectal cancer. Dis Colon Rectum 2006; 49: 816-824. 
10. Partridge J, Sbai M, Dhesi J. Proactive care of older people undergoing surgery. Aging Clin Exp Res 2018 ;30(3):253-257.

11. Bansal, N. Impact of pharmacist involvement in enhanced recovery pathways in improving patient care in those undergoing lower gastrointestinal surgery. National Institute for Health and Care Excellence Shared learning database; 2016. Last accessed $10^{\text {th }}$ January 2019. Available at: https://www.nice.org.uk/sharedlearning/impact-of-pharmacist-involvement-inenhanced-recovery-pathways-in-improving-patient-care-in-those-undergoinglower-gastrointestinal-surgery.

12. Simpson JC, Moonesinghe SR, Grocott MP et al. Enhanced recovery from surgery in the UK: an audit of the enhanced recovery partnership programme 2009-2012. British Journal of Anaesthesia 2015; 115 (4): 560-8.

13. Miah S, Dunford C, Edison M et al. A prospective clinical, cost and environmental analysis of a clinician-led virtual urology clinic. Annals of the Royal College of Surgeons of England 2018, 101(1); 30-34.

14. Institute for Healthcare Improvement for NHS England. Always events toolkit. December 2016. Last accessed $4^{\text {th }}$ January 2019. Available at https://www.england.nhs.uk/wp-content/uploads/2016/12/always-events-toolkitv6.pdf.

15. ASA House of Delegates. ASA Physical Status Classification system 2014. Last accessed $10^{\text {th }}$ January 2019. Available at http://www.asahq.org/resources/clinicalinformation/asa-physical-status-classification-system.

16. Omboni S, Caserini M. Effectiveness of pharmacist's intervention in the management of cardiovascular diseases. Open Heart 2018; 5 (1): e000687. 
17. Machado M, Bajcar J, Guzzo GC et al. Sensitivity of patient outcomes to pharmacist interventions. Part II: Systematic review and meta-analysis in hypertension management. Ann Pharmacother 2007; 41 (11):1770-81.

18. Howard R, Avery A, Slavenburg $S$ et al. Which drugs cause preventable admissions to hospital? A systematic review. Br J Clin Pharmacol 2007; 63 (2):13647.

19. McAleese P, Odling-Smee W. The effect of complications on length of stay. Annals of Surgery 1994; 220 (6): 740-44.

20. Craig $\mathrm{P}$, Dieppe $\mathrm{P}$, Maclntyre $\mathrm{S}$ et al. Developing and evaluating complex interventions: the new Medical Research Council guidance. BMJ 2008; 337:a1655.

21. Moore GF, Audrey S, Barker M et al. Process evaluation of complex interventions: Medical Research Council guidance. BMJ 2015; 350:h1258. 
Table 1. Characteristics of the study cohort

\begin{tabular}{|c|c|c|c|c|c|}
\hline & $\begin{array}{c}\text { Upper GI } \\
(\mathrm{N}=17)\end{array}$ & $\begin{array}{c}\text { Lower GI } \\
(\mathrm{N}=87)\end{array}$ & $\begin{array}{c}\text { HPB } \\
(\mathrm{N}=82)\end{array}$ & $\begin{array}{l}\text { Vascular } \\
(\mathrm{N}=60)\end{array}$ & $\begin{array}{c}\begin{array}{c}\text { Total } \\
(\mathrm{N}=246)\end{array}\end{array}$ \\
\hline \multicolumn{6}{|l|}{ Gender } \\
\hline Male & $11(64.7 \%)$ & $47(54.0 \%)$ & $62(75.6 \%)$ & $50(83.3 \%)$ & $170(69.1 \%)$ \\
\hline Female & $6(35.3 \%)$ & $40(46.0 \%)$ & $20(24.4 \%)$ & $10(20.0 \%)$ & $76(30.9 \%)$ \\
\hline \multicolumn{6}{|l|}{ Age rank (years) } \\
\hline$<50$ & $0(0.0 \%)$ & $12(13.8 \%)$ & $1(1.2 \%)$ & $1(1.7 \%)$ & $14(5.7 \%)$ \\
\hline $50-59$ & $2(11.8 \%)$ & $12(13.8 \%)$ & $7(8.5 \%)$ & $5(8.3 \%)$ & $26(10.6 \%)$ \\
\hline $60-69$ & $6(35.3 \%)$ & $30(34.5 \%)$ & $36(43.9 \%)$ & $16(26.7 \%)$ & $88(35.8 \%)$ \\
\hline $70-79$ & $9(52.9 \%)$ & $24(27.6 \%)$ & $32(39.0 \%)$ & $26(43.3 \%)$ & $91(37.0 \%)$ \\
\hline$>80$ & $0(0.0 \%)$ & $9(10.3 \%)$ & $6(7.3 \%)$ & $12(20.0 \%)$ & $27(11.0 \%)$ \\
\hline \multicolumn{6}{|l|}{ ASA Grade } \\
\hline 1 & $0(0.0 \%)$ & $10(11.5 \%)$ & $2(2.4 \%)$ & $0(0.0 \%)$ & 12 (4.9\%) \\
\hline 2 & $17(100 \%)$ & $63(72.4 \%)$ & $46(56.1 \%)$ & $19(31.7 \%)$ & 145 (58.9\%) \\
\hline 3 & $0(0.0 \%)$ & $14(16.1 \%)$ & $34(41.5 \%)$ & $41(68.3 \%)$ & $89(36.2 \%)$ \\
\hline 4 & $0(0.0 \%)$ & $0(0.0 \%)$ & $0(0.0 \%)$ & $0(0.0 \%)$ & $0(0.0 \%)$ \\
\hline 5 & $0(0.0 \%)$ & $0(0.0 \%)$ & $0(0.0 \%)$ & $0(0.0 \%)$ & $0(0.0 \%)$ \\
\hline \multicolumn{6}{|l|}{ Co-morbidity } \\
\hline Respiratory disease & $3(5.7 \%)$ & $17(5.8 \%)$ & $11(4 \%)$ & $21(8 \%)$ & $42(4.9 \%)$ \\
\hline Cardiovascular disease & $25(47.2 \%)$ & $89(30.2 \%)$ & $95(34.2 \%)$ & $\begin{array}{c}103 \\
(37.1 \%)\end{array}$ & $312(36.3 \%)$ \\
\hline Musculoskeletal disease & $6(11.3 \%)$ & $21(7.1 \%)$ & $15(5.5 \%)$ & $16(5.8 \%)$ & $38(4.4 \%)$ \\
\hline $\begin{array}{l}\text { Renal, liver and urological } \\
\text { disease }\end{array}$ & $0(0.0 \%)$ & $21(7.1 \%)$ & $16(5.8 \%)$ & $13(4.7 \%)$ & $50(5.8 \%)$ \\
\hline Vascular disease & $3(5.7 \%)$ & $13(4.4 \%)$ & $12(4.3 \%)$ & $27(9.7 \%)$ & $55(6.4 \%)$ \\
\hline Gastro-intestinal disease & $9(17 \%)$ & $49(16.6 \%)$ & $25(9 \%)$ & $20(7.2 \%)$ & $103(12 \%)$ \\
\hline Nervous system & $1(1.9 \%)$ & $18(6.1 \%)$ & $13(4.7 \%)$ & $5(1.8 \%)$ & $37(4.3 \%)$ \\
\hline Endocrine disease & $5(9.4 \%)$ & $23(7.8 \%)$ & $33(11.9 \%)$ & $14(5 \%)$ & $75(8.7 \%)$ \\
\hline $\begin{array}{l}\text { Immune system and } \\
\text { malignant disease }\end{array}$ & $1(1.9 \%)$ & $19(6.4 \%)$ & $27(9.7 \%)$ & $7(2.5 \%)$ & $54(6.3 \%)$ \\
\hline $\begin{array}{l}\text { ENT, oropharynx and skin } \\
\text { disease }\end{array}$ & $0(0.0 \%)$ & $8(2.7 \%)$ & $3(1.1 \%)$ & $5(1.8 \%)$ & $16(1.9 \%)$ \\
\hline Previous surgery & $0(0.0 \%)$ & $17(5.8 \%)$ & 28 (10.1\%) & 32 (11.5\%) & 77 (9\%) \\
\hline
\end{tabular}

(Note) GI: gastrointestinal; HPB: Hepato-pancreato-biliary ASA: American Society of Anaesthesiologists; ENT: ear, nose and throat 
Table 1. Number of high-risk medicines taken by patients and the major pharmacist interventions

\begin{tabular}{lccccc}
\hline & $\begin{array}{c}\text { Upper GI } \\
(\mathrm{N}=17)\end{array}$ & $\begin{array}{c}\text { Lower GI } \\
(\mathrm{N}=87)\end{array}$ & $\begin{array}{c}\text { HPB } \\
(\mathrm{N}=82)\end{array}$ & $\begin{array}{c}\text { Vascular } \\
(\mathrm{N}=60)\end{array}$ & $\begin{array}{c}\text { Total } \\
(\mathrm{N}=246)\end{array}$ \\
\hline Total number of patients & & & & & \\
0-3 drugs & $9(52.9 \%)$ & $34(39.1 \%)$ & $27(32.9 \%)$ & $8(13.3 \%)$ & $78(31.7 \%)$ \\
4-6 drugs & $5(29.4 \%)$ & $26(29.9 \%)$ & $33(40.2 \%)$ & $27(45.0 \%)$ & $91(37.0 \%)$ \\
$7-9$ drugs & $1(5.9 \%)$ & $20(23.0 \%)$ & $15(18.3 \%)$ & $19(31.7 \%)$ & $55(22.4 \%)$ \\
$10-12$ drugs & $0(0.0 \%)$ & $5(5.7 \%)$ & $7(8.5 \%)$ & $6(10.0 \%)$ & $18(7.3 \%)$ \\
$>12$ drugs & $2(11.8 \%)$ & $2(2.3 \%)$ & $0(0.0 \%)$ & $0(0.0 \%)$ & $4(1.6 \%)$ \\
\hline Number of interventions & $\mathrm{N}=55$ & $\mathrm{~N}=191$ & $\mathrm{~N}=112$ & $\mathrm{~N}=62$ & $\mathrm{~N}=420$ \\
\multicolumn{1}{l}{ Medicines optimization } & $30(54.5 \%)$ & $85(44.5 \%)$ & $43(38.4 \%)$ & $28(45.2 \%)$ & $186(44.3 \%)$ \\
$\begin{array}{l}\text { Peri-operative drug } \\
\text { management }\end{array}$ & $25(45.5 \%)$ & 106 & $69(61.6 \%)$ & $34(54.8 \%)$ & $234(55.7 \%)$ \\
\hline (Note) Gl: gastrointestinal; HPB: Hepato-pancreato-biliary & & & \\
\hline
\end{tabular}


Table 1. Postoperative complications identified before patients discharged from hospital

\begin{tabular}{|c|c|c|c|c|c|}
\hline & $\begin{array}{l}\text { Upper GI } \\
(\mathrm{N}=17)\end{array}$ & $\begin{array}{l}\text { Lower GI } \\
(\mathrm{N}=87)\end{array}$ & $\begin{array}{l}\text { HPB } \\
(\mathrm{N}=82)\end{array}$ & $\begin{array}{l}\text { Vascular } \\
(\mathrm{N}=60)\end{array}$ & $\begin{array}{c}\text { Total } \\
(\mathrm{N}=246)\end{array}$ \\
\hline $\begin{array}{l}\text { Number of patients with } \\
\text { complications }\end{array}$ & $13(76.5 \%)$ & $44(50.6 \%)$ & $34(41.5 \%)$ & $27(45.0 \%)$ & $118(48.0 \%)$ \\
\hline Total number of complications & $n=38$ & $n=82$ & $n=122$ & $n=33$ & $\mathrm{n}=275$ \\
\hline $\begin{array}{l}\text { Post-operative nausea and } \\
\text { vomiting }\end{array}$ & $3(7.9 \%)$ & $28(34.1 \%)$ & $17(13.9 \%)$ & $13(39.4 \%)$ & $61(22.2 \%)$ \\
\hline Ileus/obstruction & $0(0.0 \%)$ & $14(17.1 \%)$ & $0(0.0 \%)$ & $0(0.0 \%)$ & $14(5.1 \%)$ \\
\hline $\begin{array}{l}\text { Infections (chest, UTIs, } \\
\text { wound, abscess, collections) }\end{array}$ & $3(7.9 \%)$ & $19(23.2 \%)$ & $23(18.9 \%)$ & $5(15.2 \%)$ & $50(18.2 \%)$ \\
\hline Poorly controlled pain & $5(13.2 \%)$ & 5 (6.1\%) & $5(4.1 \%)$ & $2(6.1 \%)$ & 17 (6.2\%) \\
\hline Delirium/confusion & $1(2.6 \%)$ & $3(3.7 \%)$ & $13(10.7 \%)$ & $1(3.0 \%)$ & $18(6.5 \%)$ \\
\hline De-arranged U\&Es & $7(18.4 \%)$ & $2(2.4 \%)$ & $7(5.7 \%)$ & $3(9.1 \%)$ & $19(6.9 \%)$ \\
\hline Acute Kidney Injury & $1(2.6 \%)$ & $2(2.4 \%)$ & $6(4.9 \%)$ & $2(6.1 \%)$ & $11(4.0 \%)$ \\
\hline $\begin{array}{l}\text { Cardiac issues (raised BP, } \\
\text { tachycardia, atrial fibrillation) }\end{array}$ & $11(28.9 \%)$ & $1(1.2 \%)$ & $11(9.0 \%)$ & $2(6.1 \%)$ & $25(9.1 \%)$ \\
\hline $\begin{array}{l}\text { Anastomotic/bile/pancreatic } \\
\text { leak }\end{array}$ & $3(7.9 \%)$ & $3(3.7 \%)$ & $12(9.8 \%)$ & $0(0.0 \%)$ & $18(6.5 \%)$ \\
\hline Bleeding & $0(0.0 \%)$ & $3(3.7 \%)$ & $5(4.1 \%)$ & $2(6.1 \%)$ & $10(3.6 \%)$ \\
\hline $\begin{array}{l}\text { Pulmonary embolisms / } \\
\text { thrombus }\end{array}$ & $1(2.6 \%)$ & $0(0.0 \%)$ & $2(1.6 \%)$ & $0(0.0 \%)$ & $3(1.1 \%)$ \\
\hline Erratic blood glucose levels & $0(0.0 \%)$ & $0(0.0 \%)$ & $5(4.1 \%)$ & $0(0.0 \%)$ & $5(1.8 \%)$ \\
\hline Bowels not opened & $2(5.3 \%)$ & $0(0.0 \%)$ & $15(12.3 \%)$ & $1(3.0 \%)$ & $18(6.5 \%)$ \\
\hline $\begin{array}{l}\text { Drop in haemoglobin } \\
\text { requiring blood transfusion }\end{array}$ & $1(2.6 \%)$ & $0(0.0 \%)$ & $0(0.0 \%)$ & $1(3.0 \%)$ & $2(0.7 \%)$ \\
\hline Death & $0(0.0 \%)$ & $2(2.4 \%)$ & $1(0.8 \%)$ & $1(3.0 \%)$ & $4(1.5 \%)$ \\
\hline
\end{tabular}


Figure 1. Selection of study cohort

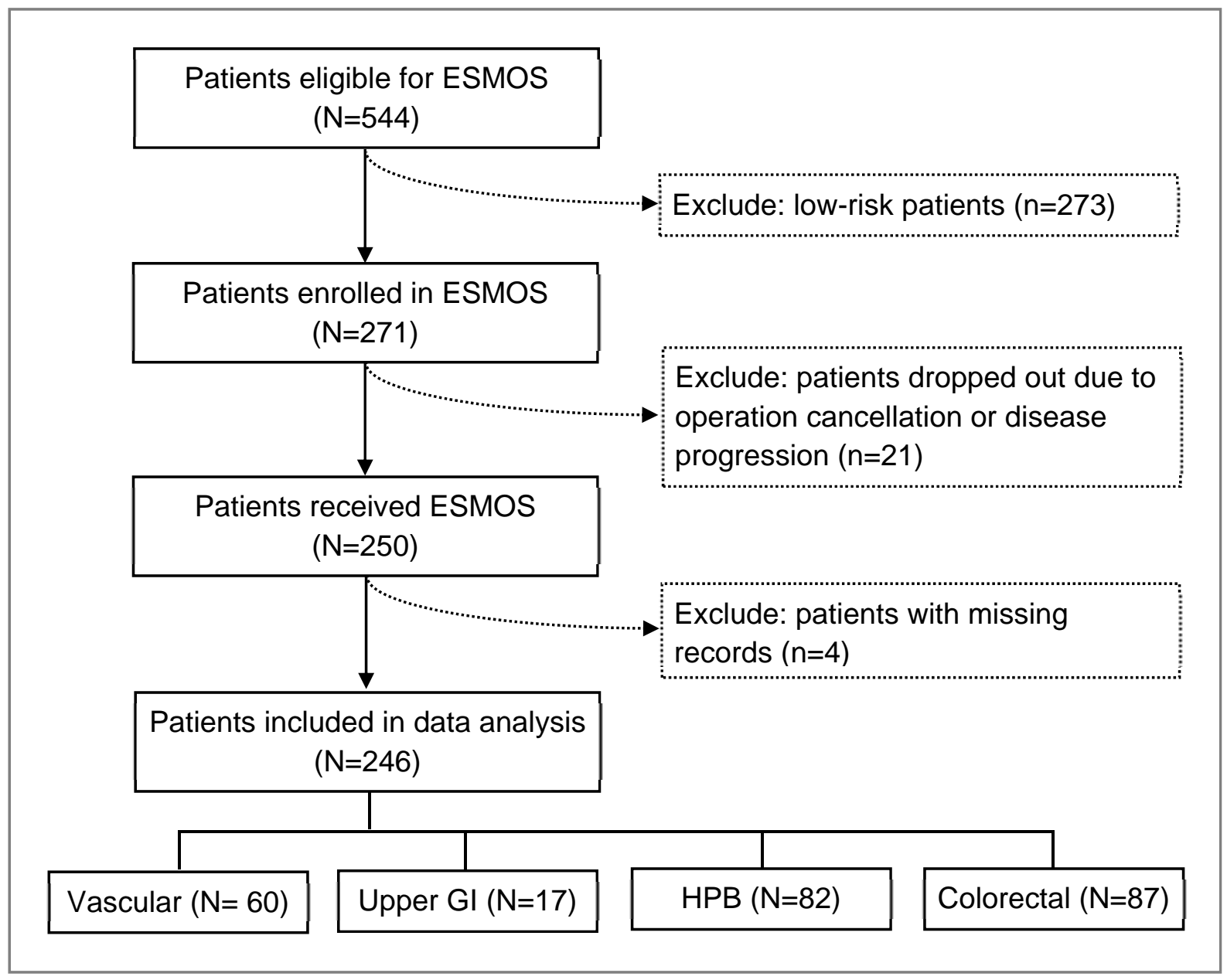


Figure 2. Number of medicines identified

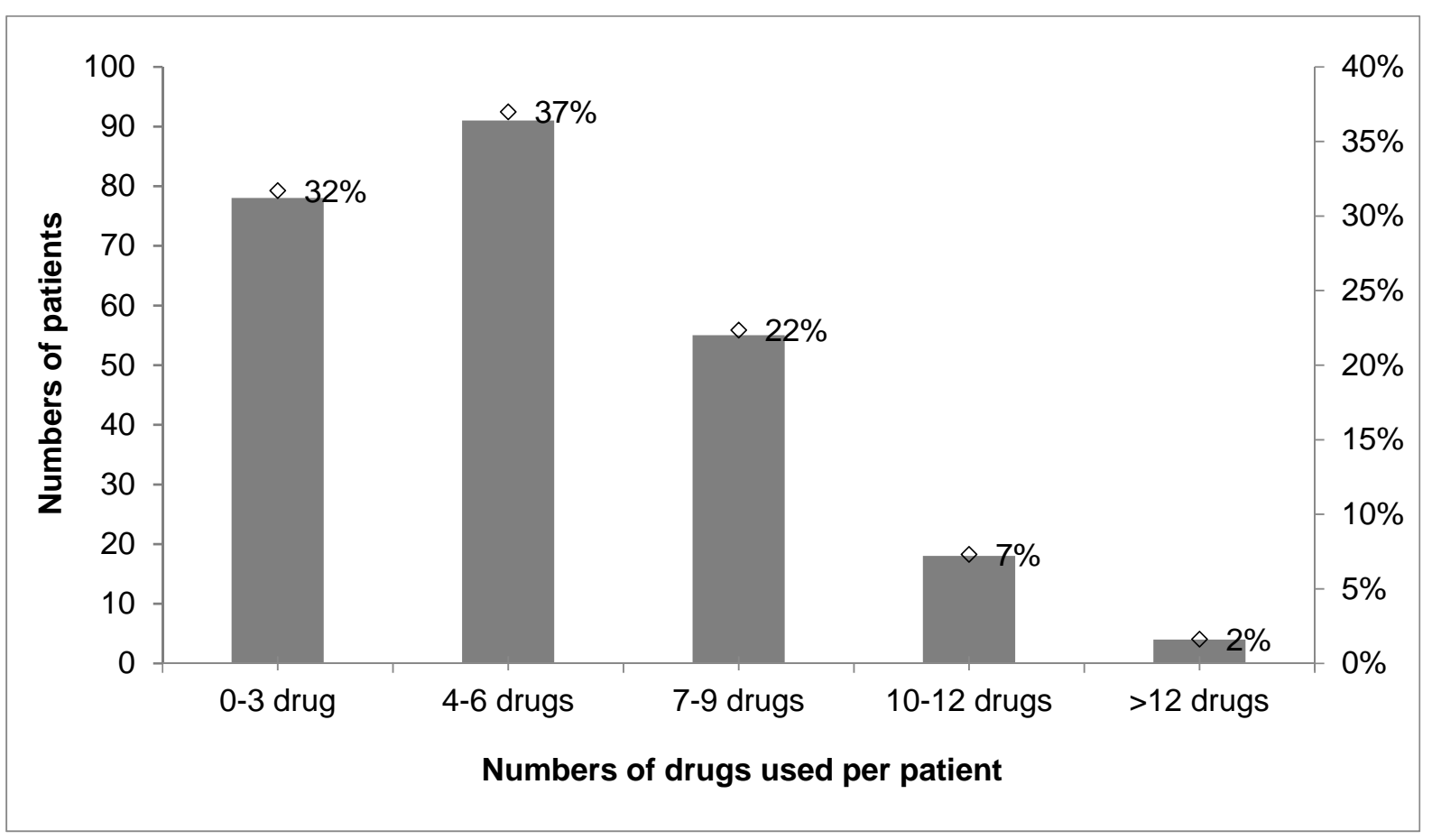


Figure 1. Comparison of expected and actual length of stay across four surgery specialities

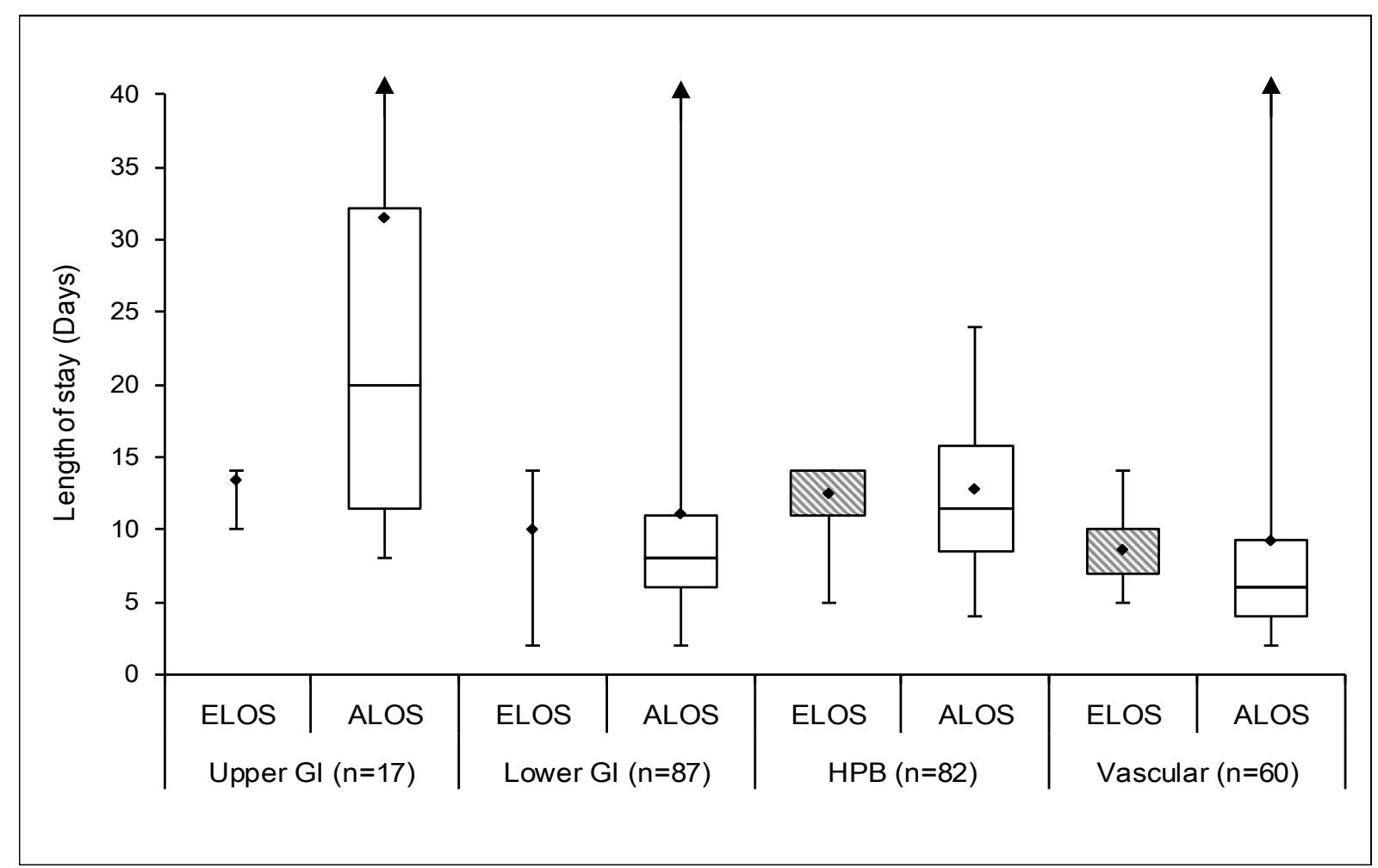

(Note) GI: Gastrointestinal; HPB: Hepato-pancreato-biliary; ELOS: expected length of stay; ALOS: actual length of stay 


\section{Appendix 1. ESMOS always events}

1. Ensure all patients are assessed by a pharmacist pre-operatively

2. Ensure patient is contacted before surgery and draw out an individually tailored plan on medicines to be stopped peri-operatively

3. Pre-operatively look for opportunities for medicines optimisation to ensure the patient is in the best possible state for surgery hence aim to reduce the incidence of postoperative complications

4. Always ensure the right regular medication is given on the day of surgery.

5. Always ensure VTE thromboprophylaxis is prescribed and administered appropriately.

6. Always ensure that postoperative nausea and vomiting is controlled.

7. A pharmacist will work with all ESMOS patients to achieve adequate pain control

8. Aim to have the take-home medication ready on the ward the day before discharge

9. All patients are asked if they have any concerns about their medicines throughout their surgical journey. 


\section{Appendix 2. Screening tool for identification of patients eligible for peri-operative ESMOS pharmacist optimised care ('high' risk patients)}

\section{A. Type of Surgery}

\begin{tabular}{|l|l|l|}
\hline Whipple & $\begin{array}{l}\text { FEVAR or not high enough risk (but high } \\
\text { AKI risk if misaligned) }\end{array}$ & Hemicolectomy \\
\hline Total Pancreatectomy & Neuroendocrine tumour surgery & Colectomy \\
\hline Liver Resection & Total gastrectomy & Pan-proctocolectomy \\
\hline Open AAA repair & Cardio-oesophagectomy & Anterior resection \\
\hline Aorto-bifemoral graft & Total oesophagectomy & Abdominoperineal resection \\
\hline
\end{tabular}

\section{B. Co-morbidities}

\begin{tabular}{|l|l|l|}
\hline Severe COPD & Thrombophilia & $\begin{array}{l}\text { Previous/current CPE } \\
\text { colonisation }\end{array}$ \\
\hline Severe Asthma & Haemophilia & $\begin{array}{l}\text { Previous/current MRSA } \\
\text { colonisation }\end{array}$ \\
\hline PFTs < 60\% of predicted & Epilepsy & Penicillin allergy \\
\hline $\begin{array}{l}\text { Coronary artery bypass graft } \\
\text { (CABG) }\end{array}$ & $\begin{array}{l}\text { Diabetes Type 1 or 2 with } \\
\text { HBA1c }>59 \text { mmol/ml }\end{array}$ & \\
\hline $\begin{array}{l}\text { Percutaneous Coronary } \\
\text { Intervention (PCI) }\end{array}$ & Carcinoid syndrome & \\
\hline $\begin{array}{l}\text { Acute coronary syndrome (ACS) } \\
\text { within one year }\end{array}$ & $\begin{array}{l}\text { Thyrotoxicosis - not yet } \\
\text { euthyroid }\end{array}$ & \\
\hline $\begin{array}{l}\text { Metallic Valve Replacements } \\
\text { (mitral or aortic) }\end{array}$ & HIV positive & \\
\hline $\begin{array}{l}\text { Previous transplant (any organ or } \\
\text { bone marrow transplant) }\end{array}$ & Parkinson's Disease & \\
\hline Congestive Heart Failure EF <50\% & Anaemia & Cirrhosis with coagulopathy \\
\hline eGFR baseline < = 60mls/min & & \\
\hline
\end{tabular}

\section{High-Risk Drugs}

\begin{tabular}{|l|l|l|}
\hline Warfarin/ Sinthrome & Monoclonal Antibody & $\begin{array}{l}\text { Sustained release opiate } \\
\text { preps (oral or topical) }\end{array}$ \\
\hline $\begin{array}{l}\text { Direct Oral Anticoagulants } \\
\text { (DOACS) }\end{array}$ & Erythropoietin/Darbepoetin & Aminophylline/theophylline \\
\hline $\begin{array}{l}\text { Treatment dose low molecular } \\
\text { weight heparin (LMWH) }\end{array}$ & Sodium Bicarbonate & Beta-blockers \\
\hline Aspirin/Clopidogrel/ Ticagrelor & Electrolyte supplements & $\begin{array}{l}\text { Any medication that requires } \\
\text { alteration pre-surgery }\end{array}$ \\
\hline
\end{tabular}




\begin{tabular}{|l|l|l|}
\hline $\begin{array}{l}\text { Ace inhibitor/angiotensin II } \\
\text { antagonists }\end{array}$ & Tacrolimus/Cyclosporin & \\
\hline Diuretics & Mycophenolate/ Azathioprine & \\
\hline Metolazone & Antiretrovirals & \\
\hline Long term oxygen therapy (LTOT) & Metformin & \\
\hline $\begin{array}{l}\text { Prednisolone/Hydrocortisone/ } \\
\text { Dexamethasone }\end{array}$ & Glitazones & \\
\hline Maximum dose steroid inhaler & Phenytoin & \\
\hline Digoxin & Sodium valproate & \\
\hline Methotrexate & Lithium & \\
\hline
\end{tabular}




\section{Enhanced Surgical Medicines Optimisation Service}

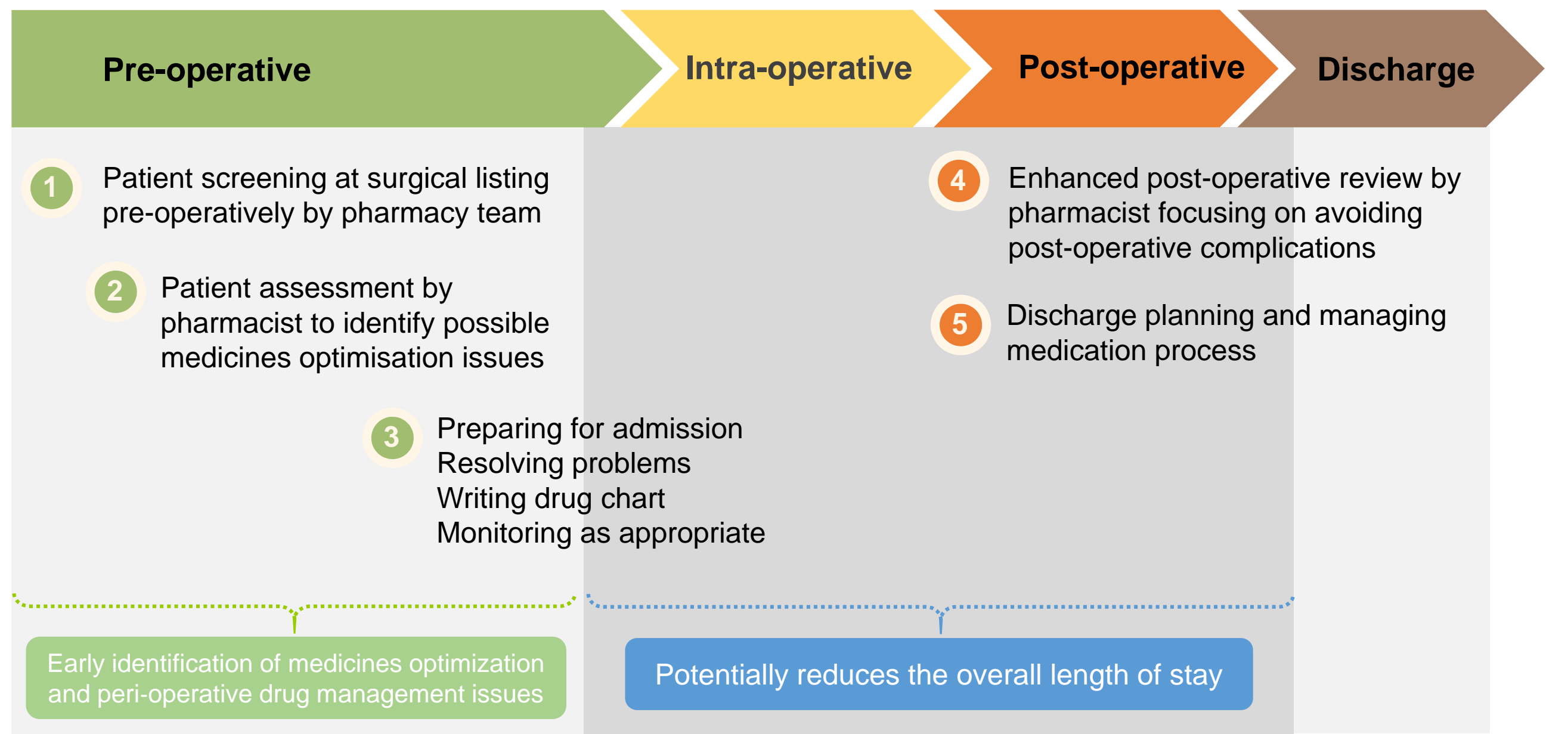

